\title{
A conversão do agravo de instrumento em agravo retido
}

\author{
Lígia Paludo ${ }^{1}$ \\ Marília do Amaral Felizardo ${ }^{2}$ \\ Nicole Bechelli ${ }^{3}$
}

\begin{abstract}
Resumo
Pretende este estudo apresentar e conceituar o recurso de agravo, bem como especificar os tipos de agravos existentes, objetivando demonstrar as hipóteses de conversão do agravo de instrumento em agravo retido e as modificações legais sobre o tema.
\end{abstract}

Palavras-Chave: Agravo; Agravo Retido; Agravo de Instrumento; Modificações Legislativas; Nova Lei.

\section{Introdução}

0 presente estudo tem por escopo demonstrar as possibilidades de conversão do agravo de instrumento em retido, traçando para isso um caminho que percorre desde a definição de agravo, em suas espécies e finalidades, passando por uma breve explanação sobre a modificação introduzida pela Lei 11.187/05 ao CPC, até chegar às formas de conversão.

A primeira parte irá se ocupar em demonstrar o conceito de agravo, sendo um gênero do recurso, interposto contra decisões interlocutórias proferidas por juiz de primeira instância, sendo suas modalidades de instrumento ou retido.

Apresentar-se-á, a possibilidade de cabimento, prazos, procedimentos, e outros aspectos conforme o Código de Processo Civil determina.

Finalizando a primeira etapa, serão especificados e diferenciados os agravos retidos e de instrumento, mencionando também o já extinto agravo interno.

Em um segundo momento, cuidar-se-á em apresentar as alterações da Nova Lei do Agravo, com alguns comentários sobre suas mudanças, em especial as mais significativas e sua receptividade por parte dos doutrinadores.

\footnotetext{
${ }^{1}$ Estudante do 4ํano de Direito da Universidade Estadual de Londrina.

${ }^{2}$ Estudante do 4ㅇ ano de Direito da Universidade Estadual de Londrina.

${ }^{3}$ Estudante do 4ํano de Direito da Universidade Estadual de Londrina.
} 
A parte final, merecedora de maior destaque, tratará da conversão do agravo de instrumento em agravo retido, de acordo com o CPC, explorando sua limitação e as implicações da irrecorribilidade da conversão determinada pelo relator.

Serão abordados também, os princípios da segurança jurídica, celeridade processual, ampla defesa e preponderância, ainda que implicitamente, pois são fundamentais ao direito processual em toda a sua extensão.

\section{0 agravo em seu gênero}

Agravo é a denominação de um gênero de recursos, sendo três as suas espécies: agravo retido, agravo de instrumento e agravo interno. Os dois primeiros citados são cabíveis contra decisões interlocutórias proferidas por juiz de primeira instância (regulados pelos arts. 522 a 529 do (PC), enquanto o último é cabível contra decisões proferidas monocraticamente pelos relatores dos tribunais (arts. 120, P.U., 527, II, 532, 545 e 557, §1응 do CPC) (CÂM ARA, 2004, p. 96).

Nesse sentido, o primeiro requisito para que se possa interpor um agravo (dos arts. 522 a 529), é que a decisão agravada seja interlocutória e proferida por juiz de primeiro grau, não sendo admitido agravo de instrumento ou retido de decisão proferida pelo Tribunal, com vistas à decisão de instância superior (STF ou STJ). Diante do que, das decisões em primeira instância, o recorrente deverá indicar um determinado ato judicial com carga decisória, ou seja, com o efeito de constituir ou desconstituir uma decisão (CARVALHO, 2003).

Logo, inviável o agravo de despacho, vez que, em regra, não possui caráter decisório (sem criar, modificar ou extinguir a demanda), mas sim procedimental, dando apenas impulso ao processo. Contudo, é possível a exceção em que 0 ato com a aparência de despacho contenha ou mascare uma decisão interlocutória, como por exemplo, vistas dos autos que prejudique 0 andamento processual para a parte contrária. Nesse caso, é plenamente cabível o agravo (CARVALHO, 2003).

O prazo para a interposição dos agravos de decisões interlocutórias (seja na forma retida ou por instrumento) é de dez dias. Proferida a decisão em audiência, conta-se daí o prazo recursal, excluindo-se, como em qualquer outra situação, o dia do começo e incluindose 0 do fim (art. 184, CPC). 
Quanto aos atos decisórios lançados nos autos, conta-se o lapso desde o primeiro dia após a intimação pelo órgão oficial nos Juízos sediados nas capitais (art 236, CPC) e nas demais comarcas onde houver jornal especialmente destinado à publicação dos atos judiciais (art. 237, CPC).

Nas comarcas onde a intimação se fizer pelo correio ou por oficial de justiça, o termo inicial é a data da juntada aos autos do aviso de recebimento ou da certidão de intimação (art. 241, I e II, CPC). Note-se que, havendo mais de um réu, o prazo só começa a correr quando o último for intimado (art. 241, III, CPC).

Até 0 advento da Lei 10.352/2001, era totalmente facultado à parte interpor 0 agravo retido ou o agravo de instrumento. Mas devido ao efeito suspensivo do agravo de instrumento, a maioria dos agravos interpostos era este.

Visando diminuir o número de recursos nos Tribunais, dar celeridade aos processos, conseqüentemente obedecendo ao princípio da economia processual e evitar a procrastinação da justiça, com agravos protelatórios, houve uma modificação significativa no capítulo III do título X do CPC.

As principais inovações da lei foram:

1) Concessão de poderes ao relator do Tribunal;

2) Estipulação como regra do agravo retido, sendo o agravo de instrumento uma exceção.

De acordo com a nova sistemática legal, após distribuídos o agravo incontinenti, o relator possui poder-dever de converter 0 agravo de instrumento em retido (objeto do presente trabalho) (art.527, II, CPC), negar seguimento, liminarmente, nos casos do art.557 (art. 527, I, CPC), atribuir efeito suspensivo ao recurso (art.558, CPC), ou deferir em antecipação de tutela a pretensão recursal (art. 527, III, CPC), requisitar informações ao juiz da causa (art. 527, IV, CPC), mandar intimar o agravado para que responda no prazo de 10 (dez) dias (art. 527, V, CPC), mandar ouvir o Ministério Público, se for o caso (art. 527, VI, $\mathrm{CPC}$ ).

Com a concessão desses poderes ao relator e a nova regra do agravo retido, evitase a suspensão do processo e dá-se maior agilidade às manobras processuais, dispensando atos processuais desnecessários. 
Antes, pairava certa dúvida quanto ao recurso cabível da decisão monocrática do relator. Sendo assim, questionava-se a propositura do mandado de segurança diante de decisões, como exemplo, que convertiam o agravo de instrumento inadmissível em agravo retido. Contudo, em observância ao art.557, $\S 10$, constata-se que 0 recurso cabível é 0 agravo interno (ou agravo por petição), em que se leva para julgamento ao órgão colegiado (CARVALHO, 2003).

A decisão do agravo interno tem caráter de acórdão (art. 163, CPC), cabendo, desta decisão, uma vez preenchidos os pressupostos específicos, recursos extraordinário e/ou especial (CARVALHO, 2003).

Após uma análise geral do agravo em seu gênero, passa-se a esmiuçar suas espécies.

0 agravo retido

Entende-se por agravo retido, o recurso (medida processual) interposto pelo advogado da parte (art.522, CPC), quando este discorda de alguma decisão interlocutória do juiz (de 1o grau), proferida no curso do processo (WIKIPÉDIA).

0 agravo em discussão é feito por petição que será dirigido ao juízo a quo e juntado aos autos do processo, onde ficará retido até ser julgado preliminarmente, pela instância superior ou tribunal, antes da apelação. Na peça devem ser descritos os pontos de discordância da decisão e a transcrição da mesma. Nesse sentido, a petição de agravo aguardará a subida do processo para o tribunal e só será julgada em caso de derrota em primeira instância. Devido a isso é que se fala que o agravo retido possui efeito devolutivo diferido, vez que não se tem urgência em pronto desfazimento da decisão anterior, nem urgência (GUIM ARÃES).

Recebido o recurso em questão, a parte contrária será intimada para que se manifeste, no prazo de dez dias. Depois de ouvida, o juiz poderá, se assim entender propício, se retratar (exercendo o juízo de retratação), modificando a decisão agravada, perdendo 0 agravo seu objeto, já que seu objetivo fora alcançado. Por outro lado, a nova decisão (que reforma a anterior) poderá ser atacada pela parte interessada através de recurso próprio (GUIM ARÃES). 
No caso de o juiz não reformar sua decisão, mas sim, confirmá-la, ficará o agravo retido nos autos e o processo seguirá normalmente até a sentença. Proferida esta, deve 0 agravante reiterar na apelação ou nas contra-razões à apelação interposta pela outra parte, requerendo expressamente ao tribunal, a apreciação do agravo. Caso contrário implicará em desistência tácita do agravo retido, que não será conhecido pelo tribunal (CÂM ARA, 2004, p. 97-99).

Assim sendo, só haverá efetivamente o efeito devolutivo, no caso de ser reiterado pelo agravante nas razões ou nas contra-razões da apelação (CÂMARA, 2004, p. 99). Cumprido o requisito legal, o agravo retido será apreciado como preliminar do julgamento da apelação (art. 523, caput e $\S 1^{\circ}$, CPC).

Existem dois subtipos de agravo retido, 0 oral e o escrito. A modalidade comum é 0 escrito, em que requer petição dirigida ao juiz da causa, contendo todos os requisitos formais básicos (como o fato e os fundamentos da impugnação, pedindo reforma da decisão, sem o preparo, entregando-se a peça recursal diretamente na secretaria ou cartório) (CÂM ARA, 2004, p. 99).

0 agravo oral por sua vez, é previsto no art. $523, \S 30$ do CPC, que estipula a interposição de agravo oral e imediato contra decisões proferidas em audiência, devendo as razões do recurso, bem como o pedido nele formulado, ser reduzidas a termo, sob pena de preclusão. Na mesma audiência, ouve-se 0 agravado e em seguida, pode o juiz se retratar (CÃM ARA, 2004, p. 99).

0 agravo de instrumento

É o recurso admitido, como exceção, contra decisões interlocutórias, em que o agravo será processado fora dos autos da causa onde se deu a decisão impugnada, formando razões e contra-razões dos litigantes para o respectivo julgamento. A peça será diretamente protocolada no juízo ad quem, ou seja, no tribunal (juízo recorrente), com o devido preparo (DireitoNet - Dicionário Jurídico).

As hipóteses de propositura do agravo de instrumento estão dispostas no art. 522 do CPC, em questões urgentes capazes de provocar danos irreparáveis, tais como:

- Houver risco de a decisão causar lesão grave e de difícil reparação à parte

- Inadmissão de apelação 
- Quanto aos efeitos em que a apelação é recebida.

Esse recurso visa dar celeridade e funcionalidade ao processo, tendo em vista que antes se interpunha 0 agravo e impetrava mandado de segurança, com pedido liminar para atribuição do efeito suspensivo ao agravo. Desta forma, a utilidade do agravo de instrumento está em evitar a repetição de atos e abrir uma única via para o ataque do ato judicial que resolve questão incidente (GUIM ARÃES).

0 pressuposto específico do agravo de instrumento é a decisão de primeiro grau que cause prejuízo à parte, ao Ministério Público (fiscal da lei), ou a terceiro, desde que não implique na extinção do processo (GUIM ARÃES).

Há ainda os pressupostos negativos, que obstam a interposição deste recurso. São eles: a) as decisões posteriores à sentença somente serão atacadas em preliminares da apelação, salvo a que indeferir esse recurso ( $\S 40$ do art. 523, CPC) - lembre-se que tal disposição diz respeito a certo processo, considerado isoladamente, ou, em outras palavras, não alcança outro processo, ainda que se instaure nos mesmos autos, como a execução de sentença, b) não será cabível também, no procedimento sumário, quanto às interlocutórias proferidas durante a audiência ou relativas a provas (art. 280, III, CPC), c) nem da decisão do juiz que admite a sua suspeição ou impedimento e ordena a remessa dos autos ao substituto legal (art. 313, primeira parte, CPC) , porque, ainda que não se trate de causa legalmente prevista, o magistrado poderia declarar suspeição por motivo de foro íntimo, inviabilizando qualquer possibilidade de revisão do ato. Cuida-se, portanto, de preclusão lógica projudicato (GUIM ARÃES).

Sempre será 0 agravo de instrumento o único recurso adequado nos casos da decisão da exceção de incompetência, na impugnação ao valor da causa e no processo de execução, no qual inexiste sentença, salvo a que extingue o processo pela satisfação do débito, pela transação ou quando se dá, por outro meio, a remissão total da dívida, e pela renúncia ao crédito (art. 794, CPC). “Assim, somente haverá interesse recursal na interposição desse tipo de agravo, porque 0 retido não comportaria reapreciação pelo tribunal" (GUIM ARÃES).

Vale lembrar que o agravo inadmissível, manifestadamente improcedente ou interposto com fundamentação que contraria súmula ou a orientação dominante do tribunal será rejeitado liminarmente pelo relator (negativa de seguimento), com base no art. 557, 
CPC. M ais ainda, se a decisão impugnada estiver em confronto com a súmula ou orientação dominante do STF ou do STJ o relator dará imediato provimento ao recurso ( $\$ 10$ do art. 557).

Depois de interposto o agravo de instrumento, é dado o prazo de 3 (três) dias, para que 0 agravante junte cópia da petição de agravo, dos documentos que o instruem e do comprovante de sua interposição aos autos principais (art. 526, CPC), dando ciência ao juiz da causa e possibilitando sua retratação, em que se ocorrida, considerará prejudicado o agravo (art. 529, CPC).

O não cumprimento do preceito é causa de inadmissibilidade do recurso, que deve ser argüida e provada pelo agravado, caso em que deve ter sido prejudicado (art. 526, P.U., $\mathrm{CPC})$.

A peça deve conter a exposição dos fundamentos de fato e de direito, as razões do pedido de reforma da decisão agravada, além do nome e endereço dos advogados que atuam no processo (art. 524, I,II, III). Também deverá ser instruída pelo agravante com as peças que irão formar o instrumento do agravo, sendo elas obrigatórias e facultativas (art. 525, CPC).

A ausência de uma das peças obrigatórias implica inadmissibilidade do recurso por falta do pressuposto recursal consistente na regularidade formal e a falta de comprovante do recolhimento das custas em deserção (art. 525, §1ํ, CPC) (CÂM ARA, 2004, p. 102).

Importante ressaltar que a distribuição do agravo previne o relator para julgar a apelação, o que permite o cumprimento do disposto no art. 559 do CPC, que impede 0 julgamento da apelação antes do agravo.

\section{M odificações introduzidas pela lei $11.187 / 05$}

Anteriormente, o CPC, em capítulo dedicado ao agravo, estabelecia sua interposição, sendo a forma retida ou de instrumento, facultada pelo agravante.

Com isso, a preferência pelo agravo de instrumento era evidente, posto que a escolha pelo agravo retido implicaria sua apreciação somente em momento posterior a sentença (NUNES).

Porém, essa livre opção, como bem explica Alexandre Freitas Câmara, sofreu importante restrição com a Lei 10.352/01, uma vez que foi conferido ao relator o poder de 
converter o agravo de instrumento em retido quando entender descabido análise do recurso de imediato (CÂM ARA, 2004, p.97).

Dessa conversão resultou uma nova possibilidade: o agravo interno da decisão de conversão (NUNES).

A medida adotada pela lei visava à diminuição do agravo de instrumento nos tribunais, facilitando a apreciação das apelações pelos mesmos (NUNES).

Como ainda permanecesse a situação de abarrotamento dos tribunais, contando ainda com mais um tipo de agravo, a Lei 11.187/05 trouxe para os artigos do Código de Processo Civil uma redação mais restritiva aos agravos de instrumento ao estabelecer 0 agravo retido como regra, não descartando o de instrumento, mas mantendo-o agora como exceção.

Assim dispõe o CPC vigente:

Art. 522. Das decisões interlocutórias caberá agravo, no prazo de 10 (dez) dias, na forma retida, salvo quando se tratar de decisão suscetível de causar à parte lesão grave e de difícil reparação, bem como nos casos de inadmissão da apelação e nos relativos aos efeitos em que a apelação é recebida, quando será admitida sua interposição por instrumento.

Outra alteração da nova lei, encontra-se presente no parágrafo terceiro do art. 523 do CPC, evocando novamente o agravo retido, oral e imediato, quando de decisão interlocutória proferida na audiência de instrução e julgamento, devendo ser posto a termo e constar as razões do agravante.

Essa mudança consiste na obrigatoriedade da oralidade, antes facultativa, posicionamento esse defendido por Câmara ao considerar o princípio da oralidade adequado à celeridade processual necessária no caso (CÂM ARA, 2004, p. 99).

Por fim, a nova Lei do Agravo modificou o art. 527 em seus incisos II, V, VI e parágrafo único.

No inciso II, o posicionamento do agravo retido como regra é reafirmado, ressalvando as hipóteses de exceção reservadas ao agravo de instrumento, expondo 0 inciso, a possibilidade do relator de, recebendo agravo de instrumento no tribunal e distribuído incontinenti, converter o agravo de instrumento em retido (salvo hipóteses reservadas ao de instrumento). 
A redação do inciso $V$ está assim redigida:

V- mandará intimar o agravado, na mesma oportunidade, por ofício dirigido ao seu advogado, sob registro e com aviso de recebimento, para que responda no prazo de 10 (dez) dias (art.525, § 2ㅇ), facultando-Ihe juntar a documentação que entender conveniente, sendo que, nas comarcas de sede de tribunal e naquelas em que o expediente forense for divulgado no diário oficial, a intimação far-se-á mediante publicação no órgão oficial;

Sobre esse inciso, Tereza Arruda Alvim Wambier teceu o seguinte comentário, de que ao se referir a juntada de documentação entendida por conveniente, é evidente que a mesma deve estar presentes nos autos, salvo se o agravado ainda não contestou (WAM BIER, 2006, p. 39).

O inciso VI, trata da manifestação do Ministério Público se for o caso, tendo o prazo de 10 (dez) dias.

E quanto ao parágrafo único, este estabelece que decisão liminar proferida nos casos de conversão de agravo de instrumento em retido, atribuição do efeito suspensivo ou ainda deferimento de antecipação de tutela, somente será passível de reforma no momento do julgamento do agravo, com exceção no caso do relator reconsiderar.

Para Tereza Arruda Alvim, essa última modificação introduzida pela Lei 11.187/05, foi a mais significativa, pois traz quase expressamente a irrecorribilidade de decisões que atribuam efeito suspensivo ao agravo (extinção do agravo interno). Cabendo a parte elaborar pedido de reconsideração, eventualmente apresentar embargos de declaração e em situações mais gravosas entrar com mandado de segurança (WAM BIER, 2006, p. 39).

Dessa forma, pode-se considerar que as mudanças ocorridas no CPC foram focalizadas no intuito de diminuir a quantidade de agravos no tribunal, indo em socorro ao princípio da celeridade e economia processual sem deixar de lado é claro, o princípio da segurança jurídica.

É notória, a opinião de alguns doutrinadores de que o recurso é um dos responsáveis pela lentidão do judiciário. 0 agravo de instrumento, pelo fato de ser analisado de imediato e ainda ter a possibilidade de efeito suspensivo, é alvo das mesmas críticas.

Com tudo isso, a nova Lei do Agravo foi acolhida com ânimo por parte da doutrina, entendendo ser significativas as reformas, perseguindo exatamente os objetivos pelos quais foram criadas. 
Por outro lado, recebeu severas críticas, entre as quais merece destaque a extinção do agravo interno ou regimental, o que abriu espaço para a propositura do mandado de segurança, sendo a interposição deste, muito mais complexa e trabalhosa que daquele. De modo a beneficiar a ampla defesa, mas prejudicar intensamente o descongestionamento do judiciário (SANTOS).

Finalizando, a Lei 11.187/05 com suas alterações ao Código de Processo Civil visa a uma melhora no ordenamento jurídico brasileiro, buscando solução mais adequada para garantir o bom funcionamento e andamento processual nos tribunais, entretanto sempre haverá brechas que gerará descontentamento e acarretará novos problemas a serem resolvidos.

\section{A conversão do agravo de instrumento em agravo retido}

Conforme já fora citado, anteriormente a Lei $n^{\circ} 11.187 / 2005$, era concedido ao recorrente a opção de escolha da espécie de agravo que achasse por bem interpor, vez que 0 artigo 522 apenas estipulava "das decisões interlocutórias caberá agravo, no prazo de 10 (dez) dias, retido nos autos ou por instrumento" (grifo nosso).

No entanto, com 0 advento do referido dispositivo legal, 0 agravo de instrumento passou a ser exceção, só podendo ser manejado em face de decisão interlocutória que possa acarretar danos irreparáveis ou de difícil reparação, assim como naquela que indefira apelação ou a julgue quanto a seus efeitos (art. 522, CPC) (CARVALHO, 2003).

Tais requisitos se explicam pelo procedimento que 0 agravo de instrumento possui e pelo objetivo de cada uma das duas espécies.

A prática da conversão do agravo de instrumento em agravo retido previsto no inciso II do artigo 527 do CPC foi criada com o intuito de diminuir a morosidade que os referidos recursos podem causar.

Considerando que o agravo retido será aquele interposto nas decisões interlocutórias que não tenham caráter urgente ou naquelas que não se manifestem quanto a apelação atravessada, nada obsta que só seja julgado em momento futuro, se após a sentença 0 agravante ainda permanecer com 0 interesse.

Um exemplo possível seria o agravo que é interposto em face de decisão interlocutória que indefere a produção de determinada prova. Nesta hipótese, se 
posteriormente advir sentença desfavorável a aquele requerente, ainda lhe caberá a apreciação de seu recurso em tempo de decorrer qualquer lesão. De outro lado, sendo-lhe favorável a sentença, o agravante não terá mais motivos para pleitear o julgamento do agravo retido.

Obviamente ocorrerá de forma diferente se no mesmo caso a demora ameaçar a obtenção da prova que se pretende produzir, como ocorreria com a prova testemunhal de alguém que padece de doença grave.

Nota-se que é um mecanismo que evita diversos atos desnecessários, já que ao mesmo tempo que conduz o agravante à espera do desenrolar normal do processo para só então reavaliar a necessidade do julgamento de seu recurso, irá lhe garantir a inocorrência da preclusão.

No entanto, é certo que quando houver periculum in mora e fumus boni iures, o fim do agravante não será afastar a preclusão, mas impedir que a demora do julgamento traga efeitos de grande monta.

Nestes casos deve-se interpor agravo de instrumento, posto que só assim o relator que recebê-lo poderá deferir, total ou parcialmente, a pretensão recursal mediante antecipação de tutela, ou ainda, poderá suspender os efeitos da decisão interlocutória nos casos de prisão civil, adjudicação, remição de bens, levantamento de dinheiro sem caução idônea ou outros que puderem resultar lesão grave e de difícil reparação (art. 527, III e art. 558 do CPC).

Logo que protocolado no tribunal ad quem (art. 524 do CPC), o relator avaliará se 0 agravo de instrumento atende as exigências do art. 557 do CPC e se deverá ser convertido para a espécie retida. Para tanto, atuará de ofício, ou seja, independentemente de pedido de uma das partes.

A decisão do relator pela conversão terá caráter irrecorrível e será obrigatória quando não for necessária a instrumentalização do agravo, posto que a Lei n 11.187/2005 retirou a faculdade que 0 art. 527, II do CPC concedia a este juiz (CÂM ARA, 2007, p. 102).

Contudo, para que a reforma do Código de Processo Civil sobre estes aspectos atinja o seu objetivo de desafogamento dos tribunais, muitos cuidados devem ser dispendidos para que não ocorra o impacto contrário, proliferando-se mandados de segurança que visem obter o efeito suspensivo dos agravos retidos (CARVALHO, 2003). 
Por outro lado, possuindo o agravo interposto 0 intuito de evitar lesão grave e de difícil reparação ou de impugnar decisão que não acolheu apelação ou se pronunciou quanto aos seus efeitos, o relator não tem o condão de proceder a transmutação e, havendo pedido, deverá conceder efeito suspensivo ou ativo - antecipando efeitos da pretensão recursal. (CARVALHO, 2003).

Todavia, deve-se ressaltar que existem algumas circunstâncias que impedem a transmudação da espécie do agravo de instrumento, pois este ato ocasionaria a perda do interesse recursal. Fabiano Carvalho em seu artigo "A conversão do agravo de instrumento em agravo retido na reforma do Código de Processo Civil" elenca como hipóteses as decisões que se pronunciam sobre o reconhecimento de conexão entre causas; concessão de prazo em dobro; impedimento; suspeição; assim como aquelas oriundas dos processos de execução, em que costumam produzir efeitos diretos e instantâneos. (CARVALHO, 2003).

No que concerne ao procedimento, não é expresso no CPC até que momento 0 relator poderá efetuar a conversão, mas a lógica nos permite acreditar que seria possível até a ocorrência de atos com ela incompatíveis, como por exemplo, a partir do momento em 0 agravo de instrumento já possui data para julgamento (CARVALHO, 2003).

A decisão que converter o agravo em retido deve ser justificada pelo relator com argumentos de fato e de direito, o que pode ser explicado, dentre outros motivos, pela certa subjetividade que os requisitos de lesão grave e de difícil reparação possuem (JACOB, 2006).

De outra monta, são mais objetivas as demais possibilidades de acolhimento de agravo de instrumento, quais sejam, as fundadas em decisão que não admite apelação e naquelas que se referem aos efeitos em que a apelação é recebida. (JACOB, 2006).

No que tange a primeira hipótese, o agravo retido seria desprovido de efeitos, já que só é julgado em grau de apelação e este não seria alcançado. Ademais, o periculum in mora estaria caracterizado pela possibilidade do trânsito em julgado da demanda e pela proximidade dos atos executórios. (JACOB, 2006).

Já com relação a decisão que se manifesta sobre os efeitos em que a apelação é recebida, o agravo de instrumento pode ser necessário para evitar a execução provisória quando a apelação não é recebida nos efeitos suspensivos, o que também evidenciaria 0 periculum in mora (JACOB, 2006). 
Na seqüência da conversão, a decisão fundamentada pelo relator juntamente com os autos convertidos em agravo retido serão encaminhados para o juiz a quo para que sejam apensados ao processo principal, de forma que terão os mesmo efeitos que um agravo assim inicialmente interposto, permitindo que 0 juiz se retrate, exigindo a reiteração para apreciação e ficando submetido aos mesmos requisitos de admissibilidade (CARVALHO, 2003).

Outra mudança advinda da Lei $n^{\circ} 11.187 / 05$ que merece ênfase é que contra a decisão do relator de conversão não mais caberá agravo interno, sendo possível apenas o pedido de reconsideração ou a reforma no momento do julgamento do agravo, conforme prevê o parágrafo único do artigo 527 (art. 527, parágrafo único do CPC) (CÂM ARA, 2007, p. 109).

No que concerne a reconsideração, não há dispositivos na lei que a regulamente, restando assim tal competência para os regimentos internos dos tribunais. Em regra, o pedido deve ser feito pelo agravante, mas há quem defenda que pode ser declarado de ofício nos casos que envolvam matéria de ordem pública, até porque forma diversa seria incoerente devido a preclusão pro judicato.

A segunda possibilidade de reforma da decisão do relator é prevista para o momento de julgamento do agravo. Trata-se de uma regulamentação nova que tem sido muito criticada, visto que a turma julgadora só poderá modificar aquelas decisões que erroneamente não procederam a modificação para a espécie retida, já que sequer terão conhecimento dos agravos convertidos e já remetidos ao juízo de origem (JACOB, 2006).

Feitas essas afirmações e embasando-se na idéia de que a reconsideração não possui natureza recursal devido o princípio da taxatividade e de não estar prevista no artigo 496, que estabelece as possibilidades de recurso, ou ainda, que mesmo encarada sobre 0 aspecto de recurso, por ser julgada pelo mesmo juízo possui pequena possibilidade de reforma, surge o impasse da irrecorribilidade da deliberação monocrática do relator (JACOB, 2006).

Na realidade, tem-se que o recurso adequado para impugnar ato proferido por um único relator seria o agravo regimental, ensejando a merecida reavaliação do colegiado do órgão, só que, no entanto, essa opção padece de validade porque foi abolida com a nova redação do parágrafo único do artigo 527. (JACOB, 2006). 
Sendo assim, muitos defendem que a abolição do agravo interno neste caso veio a violar a ampla defesa e conceder primazia ao princípio da celeridade processual. Frente a este conflito, uma solução seria analisar através da proporcionalidade que 0 ato do relator, vinculado as exigências legais, dificilmente atingiria de forma grave e definitiva os interesses das partes. (JACOB, 2006).

Neste sentido, de acordo com Ricardo Mendonça Nunes (NUNES, 2005):

Agora, como foi retirada a possibilidade de agravar internamente da decisão de conversão, os relatores, se utilizarem efetivamente 0 instituto, reduzirão a carga processual, mantendo-se somente os agravos de instrumentos que objetivam reformar decisões cujo teor realmente causem grave lesão de difícil reparação. Assim, por esse novo regime, não se afasta a recorribilidade das decisões interlocutórias. 0 controle de tais decisões continuará existindo, só que ao final, quando do conhecimento do agravo retido na apelação. Por isso, não há mácula ao princípio da segurança jurídica nem ao princípio republicano porque as decisões continuarão sendo revistas por autoridade superior na apreciação do agravo retido. 0 que ocorreu apenas foi uma preponderância processual do valor celeridade em face do valor segurança jurídica, deferindo a reapreciação de decisões interlocutórias, na busca de um processo civil de resultados.

Desta forma, frente a atual falta de previsão legal para recorrer, o caminho ainda mais indicado para o agravante inconformado com a decisão de retenção do recurso será a impetração do mandado de segurança, tendo em vista que a Súmula 267 do STF só o rejeita nas hipóteses em que há outro recurso cabível (ALVARENGA, 2006).

\section{Conclusão}

Diante de todo o exposto, torna-se possível conceber o recurso com regime de agravo de maneira mais aprofundada, com ênfase as probabilidades de conversão, conforme 0 artigo 527 do CPC, em seu inciso II.

Um aspecto relevante e bastante polêmico é a determinação quase expressa do artigo de não se poder recorrer dessa conversão.

Nesse sentido, as transformações inseridas pela Lei 11.187/05, sendo em parte acolhida de maneira favorável e por outro lado criticada, deve-se muito a questão da irrecorribilidade da conversão.

Como a intenção das modificações no Código de Processo Civil é de desobstruir o judiciário, preza-se pelo princípio da celeridade processual. Há quem defenda que a 
mudança ocasionou a preponderância da celeridade sob a ampla defesa e quem se posiciona em sentido contrário, de que extinguindo o agravo interno (por conta da irrecorribilidade da conversão) abriu-se caminho ao mandado de segurança, o que exalta a ampla defesa, mas deixa a desejar a celeridade, ou seja, não só fugiu-se do objetivo das alterações, mas também originou maior trabalho aos tribunais.

0 trabalho exposto mostra todos os possíveis ângulos da reforma, com as vantagens, desvantagens e com a disputa entre os princípios em relação a qual deve se sobressair.

Dessa forma, sugere-se a necessidade de que o princípio da proporcionalidade deve reger, não descartando os variados posicionamentos sobre o tema, buscando com isso uma visão mais extensa.

\section{Referências}

ALVARENGA, José Eduardo de. 0 recurso de agravo e a Lei 11.187/2005. Direitonet, 16 mar. 2006. Disponível em: «ttp://www.direitonet.com.br/artigos/x/25/14/2514/ >. Acesso em: 21 abr. 2008.

CÂM ARA, Alexandre Freitas. LIÇÕES DE DIREITO PROCESSUAL CIVIL, vol.II, 9 ed., Lúmen Júris: Rio de Janeiro, 2004.

. Lições de Direito Processual Civil. 14. ed. Rio de Janeiro: Lúmen Júris, 2007. v. 2.

CARVALHO, Fabiano. A conversão do agravo de instrumento em agravo retido na reforma do Código de Processo Civil. Jus Navigandi, Teresina, v. 8, n. 428, 8 set. 2004. Disponível em: বttp://jus2.uol.com.br/doutrina/texto.asp?id=5660>. Acesso em: 21 abr. 2008.

DIREITONET. Disponível em:

«ttp://www.direitonet.com.br/dicionario_juridico/x/63/11/631/>.

GUIM ARÃES, José Lázaro Alfredo. 0 novo sistema de recursos no Código de Processo Civil. Módulo 3 - Agravo. Disponível em:

বhttp://paginas.terra.com.br/educacao/teia/agravo.htm>.

JACOB, Luiz Guilherme de Almeida Ribeiro. Notas à Lei no 11.187/2005. Altera o CPC para conferir nova disciplina ao cabimento dos agravos retido e de instrumento. Jus Navigandi, Teresina, v. 10, n. 921, 10 jan. 2006. Disponível em:

«ttp://jus2.uol.com.br/doutrina/texto.asp?id=7827>. Acesso em: 21 abr. 2008. 
NUNES, Ricardo M endonça. Lei $\mathrm{n} 011.187 / 05$ : o novo regime do recurso de agravo. Jus Navigandi, Teresina, v. 10, n. 857, 7 nov. 2005. Disponível em:

«ttp://jus2.uol.com.br/doutrina/texto.asp?id=7558>. Acesso em: 21 abr. 2008.

PRESTES, Lisiê Ferreira. A conversão do agravo de instrumento em retido: a reforma introduzida pela Lei 11.187/05. Boletim Jurídico, Uberaba/M G, a. 5, n. 265. Disponível em: বhttp:// www.boletimjuridico.com.br/doutrina/texto.asp?id=1941>. Acesso em: 21 abr. 2008.

WIKIPÉDIA. Disponível em: ঝttp://pt.wikipedia.org/wiki/Agravo_retido>. 